\title{
Auricular Multiple Tophi Presenting as Painful Bilateral Nodules: A Case Report and Literature Review
}

\author{
Jeong Hwan Choi, MD \\ Department of Otorhinolaryngology-Head and Neck Surgery, Sanggye Paik Hospital, \\ Inje University College of Medicine, Seoul, Korea
}

\begin{abstract}
- ABSTRACT -
Gout tophus is most commonly found in the lower extremities such as toes and ankles. The auricle is a rare site for gout tophi. Although auricular tophus (AT) is not life threatening, it is important because it can be misdiagnosed as other diseases including malignancy. ATs are firm deposits of crystallized uric acid, which may gradually grow at the subcutaneous layer of the auricle. ATs can be treated with dietary modification and medication for a long time. When pain persists, cosmetic deformity is concerned, or prompt resolution of those symptoms are required, surgical excision is worth considering. Here, we report the case of a patient presenting with multiple bilateral auricular painful nodules. Thorough questioning regarding medical history revealed that the patient had a history of untreated gout. Histopathological examination confirmed the diagnosis of AT. So, we report this case with review of literatures. (J Clinical Otolaryngol 2020;31:57-62)
\end{abstract}

KEY WORDS: Ear auricle · Gout · Crystal arthropathies.

\section{Introduction}

Gout is a systemic metabolic disease which can manifest as arthritis characterized by uric acid crystal deposition (tophus) around joints and subconnective tissue due to long standing hyperuricemia. ${ }^{1)}$ Accompanying inflammation can lead to pain, swelling, and redness of the affected joints.

Some causal factors that can induce gout include genetic susceptibilities; aging; high nutrition; purinerich diets; being overweight; certain medications like cyclosporine, anti-tuberculosis regimen with pyrazinamide, thiazide, and aspirin; certain medical conditions including uncontrolled hypertension and metabolic

논문접수일 : 2019년 12월 21일

논문수정일 : 2020년 3월 10일

심사완료일 : 2020년 3월 26일

교신저자 : 최정환, 01757 서울 노원구 동일로 1342

인제대학교 의과대학 상계백병원 이비인후과

전화 : (02) 950-1104·전송 : (02) 935-6220

E-mail:choijh92@paik.ac.kr syndrome such as diabetes; impaired renal function; and heavy drinking of alcohol or sweetened drinks. ${ }^{1,2}$

Single joint arthritis at the early stages of gout usually turns into multiple tophi formations in the body within two decades. Most tophi develop in advanced stages of poorly controlled gout and are usually found at the lower extremities such as the toes, ankles, knees, and fingers. Manifestations of tophi are seldom encountered in the field of otolaryngology. Few cases of tophaceous deposits in the auricular helix, middle ear, larynx, cricoarytenoid joint as well as gouty arthritis of the temporomandibular and sternoclavicular joint have been reported in the literature. ${ }^{1,3-6)}$ Infected tophi can cause pain and restrict joint movement. Tophi can be controlled via nonsteroidal anti-inflammatory drugs, steroids, and urate-lowering drugs (e.g., allopurinol, benzbromarone, probenecid, colchicine, pegloticase), surgical removal, or hemodialysis. Surgical interventions can be worth considering when prompt removal is required for relief of severe pain due to nerve compression. 
As auricular tophi (ATs) do not cause any auricular functioning defect, both patients and clinicians seldom express concern about ATs and tend to neglect it. However, it is important to differentiate auricular masses from other diseases including malignancy.

\section{Case Report}

A 52-year-old male hypertensive patient presented at a local dental clinic with a 1-year history of multiple bilateral auricular painful nodules. He had scratched off several nodules previously; however, new ones had appeared. Since then, the numbers and size of the nodules had been gradually increasing. Although there had been no discomfort initially, an increase in size and numbers of the nodules led to pain and tenderness during sleeping on the left side.

Physical examination revealed 2 to $5 \mathrm{~mm}$ sized several yellow-white chalky oval nodules surrounded with mild erythema on the anterior side of both auricles, mostly at the helix. These were very superficial, wellcircumscribed, firm, and tender (Fig. 1). A thorough questioning regarding previous medical history revealed that he had untreated gout for several years. He had repeated acute gout attacks in his right toe and left ankle joint 4 years ago. The initial pain was relieved by taking short-term antigout medication (allopurinol). He also had a history of alcoholic hepatitis due to a habit of drinking an average of two alcoholic beverages per day.

His serum uric acid level was found to be elevated at $9.5 \mathrm{mg} / \mathrm{dL}$. We counseled the patient on the presumed diagnosis of ATs and the pros and cons of surgical removal of the auricular nodules. After careful consideration for pain relief, cosmesis, and pathologic confirmation, the patient provided consent for excisional biopsy of the painful nodules on the left side.

During excision, a $1 \mathrm{~cm}$ sized skin incision was made on the skin just above the nodule. After elevation of the skin flap, the very superficial nodule was relatively easily detached from the surrounding soft tissues as it was not embedded inside the perichondrium. After removal of the other nodules in a similar manner, the skin flaps were repositioned and sutured. During the procedure, some white chalky or pasty substance exuded from the nodules. A compressive dressing with adhesive surgical tapes was applied.

The specimens consisted of 3 irregularly shaped
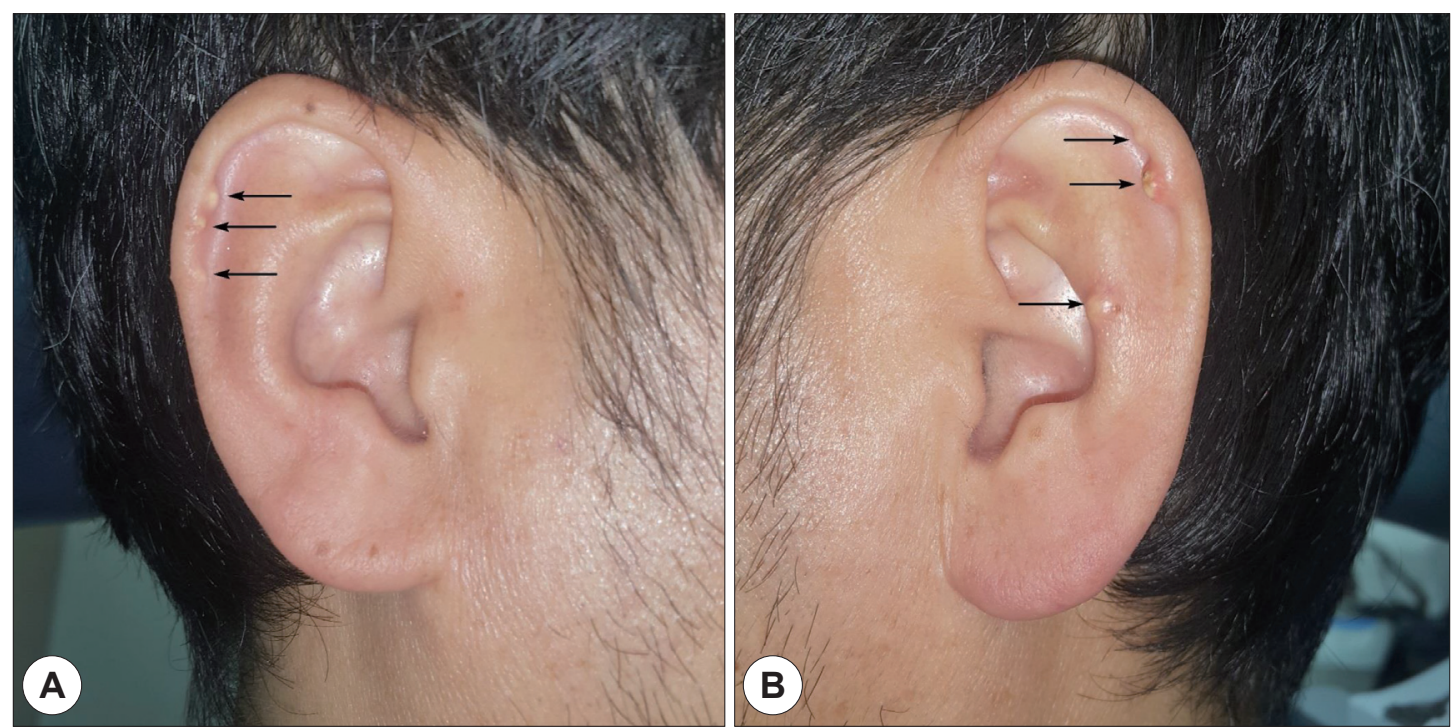

Fig. 1. The patient's right (A) and left (B) auricles. There are multiple $2-3 \mathrm{~mm}$ firm nodules (arrows) over the helix. Yellow-white chalky oval nodules are firm, tender, well-circumscribed, and surrounded with mild erythema. 
pieces of soft yellowish cyst like tissue (Fig. 2). Light microscopy revealed a basophilic granular matrix with foreign giant cells that were surrounded with dissolved needle-shaped spaces (Fig. 3). These findings were consistent with ATs. The patient was followed up for 3 months and there was no evidence of recurrence during this period.

\section{Discussion}

When auricular nodules are detected, various causes can be suspected. Clinical diagnosis of such nodular lesions can be quite difficult. Clinically, the differential diagnosis included sebaceous cyst, epidermal and dermoid cyst, chondrodermatitis nodularis helicis, actinic keratosis, keloid, verruca vulgaris, amyloids, elastotic nodules, weathering nodules, rheumatoid nodules, sarcoid nodules, tophaceous gout, sarcoidosis, leishmaniasis, leprosy, skin neoplasia including hemangioma, keratoacanthoma, chondroma, lipoma, schwannoma, neurolimemmoma, or even malignancies such as basal cell caricinoma or squamous cell caricinoma. ${ }^{7)}$

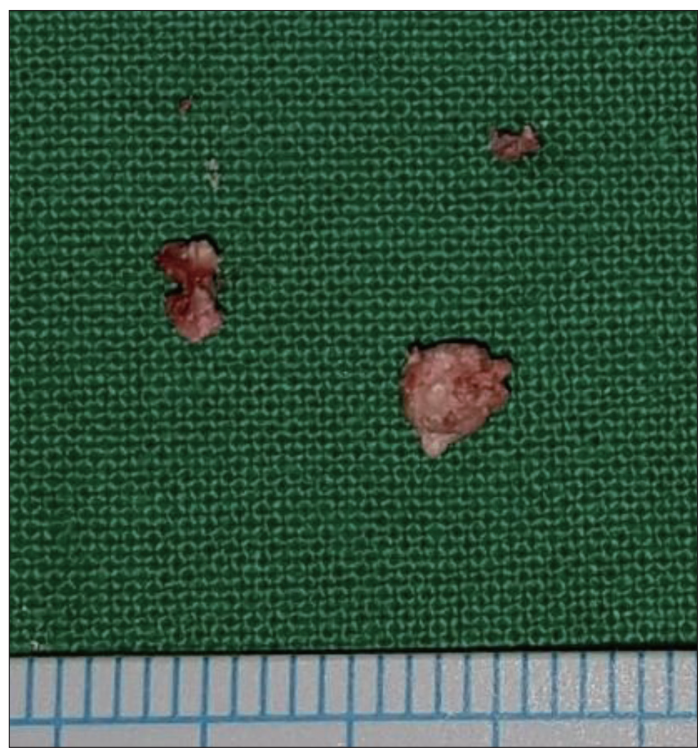

Fig. 2. Gross findings of the auricular tophi. Specimens are composed of 3 irregularly shaped pieces of soft gray, tan, and yellowish tissue. The sizes of the tophi are $0.1,0.2$, and $0.3 \mathrm{~cm}$, respectively.
A pathological examination is important to rule out the possibility of malignancy. In this case, we were able to suspect AT from the beginning, because a thorough questioning of medical history revealed that the patient had a long standing history of uncontrolled gout.

When the serum uric acid level is above $7.0 \mathrm{mg} / \mathrm{dL}$, uric acid crystals form a tophi in subcutaneous layer.
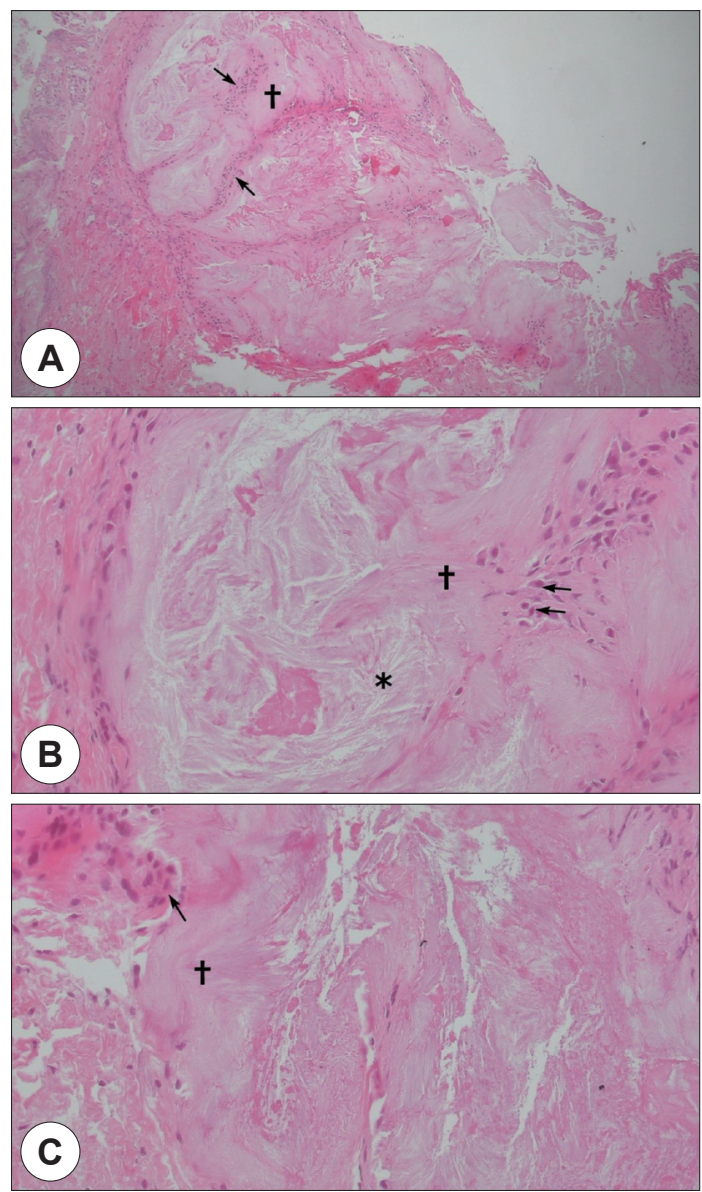

Fig. 3. Histologic findings of the formalin-fixed specimen revealed using light microscopy (A). Under low-magnification, abundant giant cells (arrow) surround the amorphous matrix $(\dagger) .(\mathrm{H} \& \mathrm{E}, \times 4)(\mathrm{B})$. Under intermediatemagnification, the pale basophilic matrix $(\dagger)$ surrounds the needle-shaped radial arranged spaces (asterisk), which correspond with outlines of uric acid crystals that have been dissolved by formalin-based preservatives. The matrix $(\dagger)$ is also surrounded by abundant giant cells (arrow) $(\mathrm{H} \& \mathrm{E}, \times 40)(\mathrm{C})$. Under high-magnification, the amorphous pink basophilic proteinaceous matrix $(\dagger)$ is surrounded by abundant foreign body giant cells (arrow) $(\mathrm{H} \& \mathrm{E}, \times 100)$. 


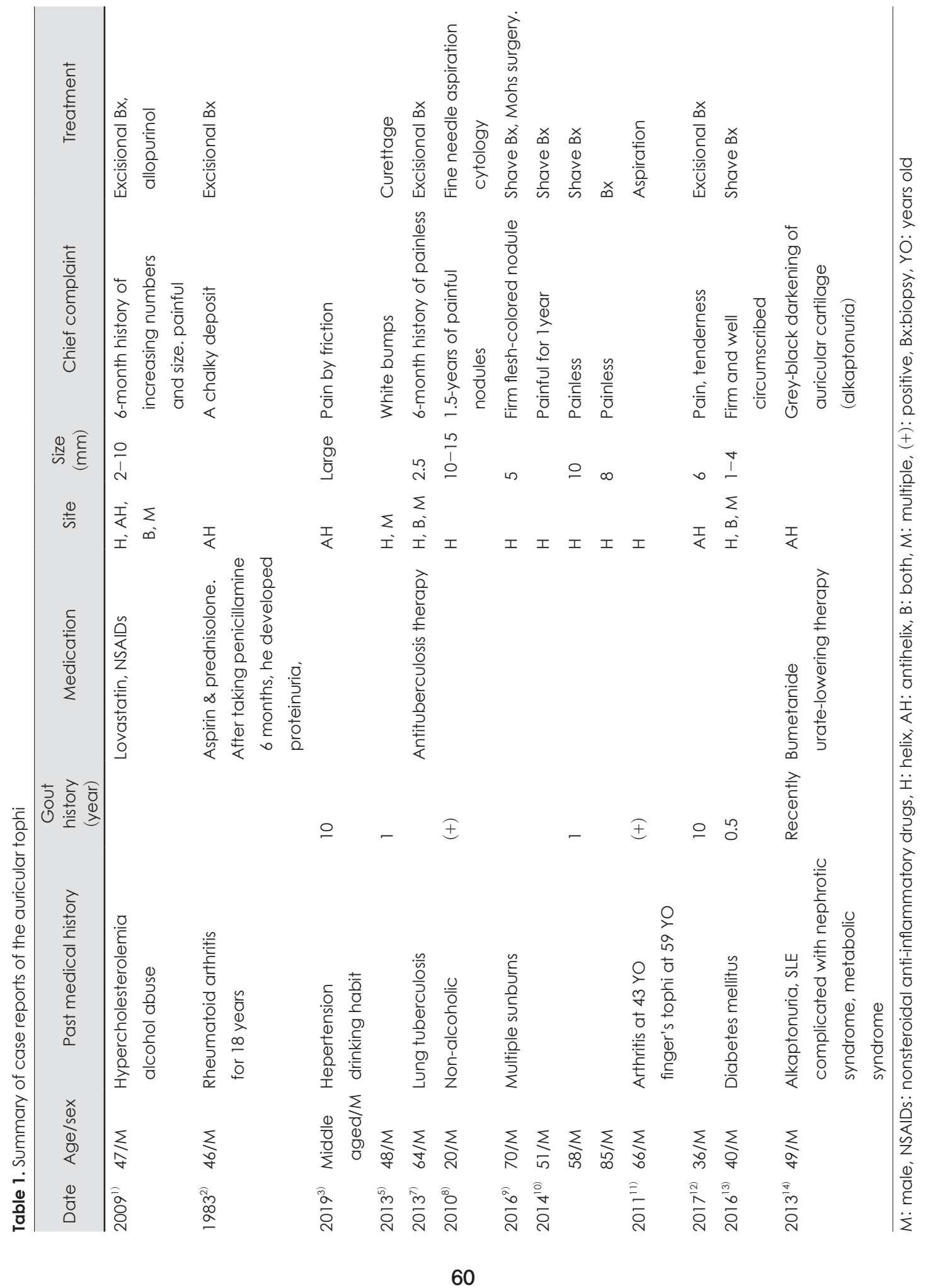


These tophi cause tenderness and redness in surrounding tissues and joint spaces. Thereafter, tophi can damage joints, destroy cartilage, and cause nerve compression leading to bone erosion and restriction of joint movement. The incidence of tophi formation is positively correlated with the serum uric acid level and the duration of gout. Over time, tophi formation as a result of gout can lead to significant deformity and disability, as it becomes harder to move the affected joints.

Grossly, gout tophi appear as white chalky stone. When histopathologically examined, they appear as a pale basophilic granular matrix surrounded by needlelike space. ${ }^{7)}$ These radially arranged spaces represent outlines of uric acid crystals that have been dissolved by formalin. Fixation in alcohol is more helpful in identifying uric acid crystals and hence, we should consider submitting excised specimens suspected to be gout tophi in both formaldehyde and ethanol.

While uncommon, tophus deposition in the head and neck has been described in a number of sites outside of the ear. ${ }^{6}$ However, a PubMed search yielded just a few articles specifically addressing ATs (Table 1). ${ }^{1-3,5,7-14)}$ Interestingly, all of the patients were male. Gout itself, is more common in males. Male to female ratio is $7: 1$ to $9: 1$ but in people over 65 years old the ratio is reduced to $3: 1{ }^{15-17)}$ The estrogenic hormones are uricosuric and therefore protective against hyperuricemia and gout. During menopause the estrogen levels drop and women with risk factors such as obese, become more likely to develop hyperuricemia and gout. ${ }^{18)}$

The head and neck regions involved include the arytenoid, true or false vocal cord, hyoid bone, thyroid cartilage, cricoarytenoid joint, subglottis, soft tissues of the nasal dorsum, nasal septum, temporomandibular joint, soft palate, cervical spine, and glossoepiglottic ligament. $^{1)}$

Besides hyperuricemia, a low body temperature and reduced blood flow can result in formation of AT. ${ }^{19)}$ Furthermore, the auricular cartilage might be a predisposing site for tophus formation, similar to that in other joints. ${ }^{19)}$

Tophi of the helices are generally asymptomatic and nontender; however, tophi can become large, inflamed, and ulcerated, causing pain and discomfort. ${ }^{1)}$

In some reported cases, AT was the initial and only sign of gout in the patient, ${ }^{1)}$ and thus the possibility of gout tophus should be considered in patients with auricular nodules. Thorough history taking, physical examination, serum uric acid level test, and pathologic confirmation are key to establishing the correct diagnosis. Fine needle aspiration to identify crystals might be helpful. Combination treatment with dietary modification and anti-hyperuricemic therapy (e.g., allopurinol or probenecid) has been shown to reduce the size of lesions and prevent future tophi formation. However, these results may take months, warranting excision of large and symptomatic lesions. ${ }^{20)}$ Surgical removal is reserved for tissue diagnosis, prompt pain relief by inflammation, and ulceration overlying the skin, or for cosmetic reasons and improvement in joint movement.

\section{Conclusion}

Initially asymptomatic ATs can become inflamed and ulcerated through the overlying skin thereafter. It is important to be aware of this presentation to prevent misdiagnosis and provide appropriate treatment. When pain persists, cosmetic deformity is concerned, or prompt resolution of symptoms are required, surgical excision is worth considering.

\section{REFERENCES}

1) Griffin GR, Munns J, Fullen D, Moyer JS. Auricular tophi as the initial presentation of gout. Otolaryngol Head Neck Surg 2009;141:153-4.

2) Hollingworth P, Scott JT, Burry HC. Nonarticular gout: hyperuricemia and tophus formation without gouty arthritis. Arthritis Rheum 1983;26:98-101.

3) Nakano Y, Otsuka F. Auricle Pain Due to Tophi. Intern Med 2019;58:453.

4) Chabra I, Singh R. Gouty tophi on the ear: a review. Cutis 2013;92:190-2

5) Elam A, McCleskey PE. Curettage as an acceptable treatment for gouty tophi on the ear. JAMA Dermatol 2013;149: 245-6.

6) Arlandis M, Molina V, Vanes S, Chiner E. Acute respira- 
tory failure due to chronic tophaceous gout with laryngeal and bronchial involvement: an unusual complication. Arch Bronconeumol 2018;S0300-2896(17)30439-8.

7) Chang HJ, Wang PC, Hsu YC, Huang SH. Gout with auricular tophi following anti-tuberculosis treatment: a case report. BMC Res Notes 2013;6:480.

8) Koley S, Salodkar A, Choudhary S, Bhake A, Singhania $\mathrm{K}$, Choudhury M. Tophi as first manifestation of gout. Indian J Dermatol Venereol Leprol 2010;76:393-6.

9) Sutton L, Parekh P. Perforating gout of the ear. Dermatol Online J 2016;22(10):13030/qtlvn208xw.

10) Morrissey KA, Garcia-Albea V, Goldberg LJ. Pseudocarcinomatous hyperplasia involving the ear from gout: a diagnostic pitfall. J Cutan Pathol 2014;41:42-4.

11) Kisacik B, Kasifoglu T. Chronic tophaceous gout. Int J Dermatol 2011;50:495-6.

12) Kuo CY, Wang CH. Auricular solitary gouty tophus in a young adult. Ear Nose Throat J 2017;96:52-5.

13) Smith JA, Kessler M, Culpepper K. Multiple superficial white nodules on the bilateral helical rims. Cutis 2016;
97(3):166, 175-6.

14) Boumans D, Haagsma CJ. Black and white: alkaptonuria and gout. Rheumatology 2013;52:1700.

15) Mahajan A, Tandon VR, Sharma S, Jandial C. Gout and menopause. J K Science 2007;9(1):50-1.

16) Souza AWS, Fernandes V, Ferrari AJL. Female gout: clinical and laboratory features. J. Rheumatol 2005;32(11): 2186-8.

17) Hak AE, Choi HK. Menopause, postmenopausal hormone use and serum uric acid levels in US women? The third national health and nutrition examination survey. Arthritis Res Ther 2008;10(5):120.

18) Harrold LR, Yood RA, Mikuls TR, Andrade SE, Davis J, Fuller J, et al. Sex differences in gout epidemiology: evaluation and treatment. Ann Rheum Dis 2006;65:1368-72.

19) Loeb JN. The influence of temperature on the solubility of monosodium urate. Arthritis Rheum 1972;15(2):189-92.

20) Caldas CA, Fuller R. Excellent response to the clinical treatment of tophaceous gout. Clin Rheumatol 2007;26:1553-5. 